\title{
Diversidade racial e de gênero: análise da comunicação do cooperativismo de crédito ${ }^{1}$
}

\author{
Racial and gender diversity in communication of credit unions
}

\author{
Jéssica Suzana Magalhães Cardoso ', Ivonete da Silva Lopes " \\ ' Universidade Federal de Viçosa, SC. jessica.smcardoso@gmail.com \\ " Universidade Federal de Viçosa, SC. ivonetesilvalopes@gmail.com
}

\section{RESUMO}

Este trabalho analisa sob a perspectiva racial e a de gênero a comunicação feita pelo Sistema de Cooperativas de Crédito do Brasil (Sicoob) e pelo Sistema das Cooperativas de Crédito Rural com Interação Solidária (Cresol). Os vídeos disponibilizados pelos dois sistemas de crédito no YouTube, entre abril e outubro de 2017, serviram de base para o estudo das representações de negros e mulheres. Os dados empíricos foram analisados pelo método da análise de conteúdo. A pesquisa revelou que a representatividade racial na comunicação é praticamente inexistente; no tocante às mulheres (sejam elas brancas ou não brancas), quando aparecem, são figurativas e reproduzem padrões tradicionais de gênero. Aponta ainda que a comunicação deste setor está permeada por estigmas e contribui para a validação de padrões conservadores tanto racial quanto de gênero.

Palavras-chave: cooperativas de crédito, comunicação, diversidade.

\footnotetext{
${ }^{1}$ Pesquisa desenvolvida no âmbito do edital PIBIC/CNPq 2017-2018 na Universidade Federal de Viçosa (UFV). Uma versão desse artigo foi apresentada no $5^{\circ}$ Encontro Brasileiro de Pesquisadores em Cooperativismo (EBPC-2019), com o título "Cooperativismo de crédito e diversidade: análise das campanhas de comunicação Sicoob e Cresol".
} 


\section{ABSTRACT}

This paper analyzes the racial and gender perspective in communication made by Sistema de Cooperativas de Crédito do Brasil (Sicoob) [Brazilian Credit Union System] and Sistema das Cooperativas de Crédito Rural com Interação Solidária (Cresol) [Rural Credit Union System with Solidarity Interaction]. This study examines both credit union's videos published on YouTube from April to October 2017. Although the cooperativism have social commitment among their principles, this study points out that racial representation is practically nonexistent in communication. Women are more visible, however, they are not protagonists, their roles in the videos reproduce gender and racial patterns.

Keywords: credit union, communication, diversity.

\section{INTRODUÇÃO}

As discussões sobre a diversidade na comunicação têm ganhado maior visibilidade no contexto brasileiro, especialmente quando se trata da representação de negros, grupo racial que tradicionalmente é ocultado do espaço midiático ou aparece de forma estereotipada. A prática da estereotipagem, segundo Hall (2016), envolve relações de poder assimétricas de um grupo hegemônico que pode representar o outro. Negros e mulheres, por exemplo, são reduzidos a poucas características tidas como naturais.

Ao trazer o tema diversidade para este trabalho, destaca-se que a comunicação é apenas uma de suas dimensões, a mais visível, portanto alvo maior de críticas. Todavia não se pode deixar de mencionar que algumas empresas incorporam o discurso da pluralidade de forma inspiradora no marketing, mas, ao se observar seus espaços físicos - os postos de trabalho, pode ser verificado que esses não refletem a mesma heterogeneidade da publicidade (BALDISSERA; ARAÚJO, 2007).

Feita essa ressalva, este artigo traz resultados de uma pesquisa sobre a perspectiva comunicacional da diversidade no cooperativismo de crédito, um dos principais ramos do cooperativismo brasileiro. ${ }^{2}$ As cooperativas deste setor

\footnotetext{
${ }^{2}$ Os demais ramos do cooperativismo são: educacional, consumo, trabalho, produção, turismo e lazer, transporte, infraestrutura, habitacional, mineral, especial, saúde e agropecuário.
} 
representam cerca de $18 \%$ das instituições que prestam diversos tipos de serviços financeiros à população brasileira e possuem cerca de 7,5 milhões de cooperados (OCB, 2018). ${ }^{3}$ O movimento cooperativista é uma iniciativa que visa incentivar o trabalho coletivo de forma a beneficiar seus membros e possibilitar a autonomia econômica deles. Entre os seus sete princípios ${ }^{4}$, destacamos dois: a educação, a formação e a informação; e aquele que versa sobre o interesse pela comunidade. Esses preceitos indicam que as organizações cooperativistas devem se preocupar com a educação e a formação assim como auxiliar nos desenvolvimentos econômico e social do local onde estão imersas.

Os princípios cooperativistas são um dos fatores que o diferenciam do setor privado (Aliança Internacional de Cooperativas - $\mathrm{ACl}, 1995)^{5}$. Em tese, a atividade é guiada por maior comprometimento social, o que leva ao pressuposto de que negros e mulheres poderiam ser representados de forma plural na comunicação. Para tanto, analisa-se como a questão racial e de gênero são incorporadas pelo Sistema de Cooperativas de Crédito do Brasil (Sicoob) e pelo Sistema das Cooperativas de Crédito Rural com Interação Solidária (Cresol). São estudadas as representações de negros ${ }^{6} \mathrm{e}$ mulheres nos vídeos disponibilizados por ambas as centrais em seus respectivos canais no YouTube. O período selecionado foi de seis meses, entre abril e outubro de 2017.

\footnotetext{
${ }^{3}$ Disponível em: <http://www.mundocoop.com.br/wpcontent/uploads/2018/07/ANUARIO_COOPERATIVISMO_2018.pdf>. Acesso em: 15 ago. 2018.

${ }^{4}$ Os princípios do cooperativismo são: 1ำ adesão livre e voluntária; 2ำ gestão democrática; 3o participação econômica; 40 autonomia e independência; 50 educação, formação e informação, 60 intercooperação e 70 interesse pela comunidade. Disponível em: http://www.ocb.org.br/o-que-e-cooperativismo>. Acesso em 6 de abr. 2018.

${ }^{5}$ Disponível em: https://www.ica.coop/en/cooperatives/cooperative-identity\#definition-of-a-cooperative. Acesso em: 28 de janeiro 2020.

${ }^{6}$ Negros, de acordo com Santos (2014), corresponde a junção das categorias de classificação pretos e pardos do Instituto Brasileiro de Geográfica e Estatística - IBGE.
} 


\section{REFERENCIAL TEÓRICO}

\subsection{Categorias raça e gênero}

Trabalhar a representatividade dos negros e das mulheres pelas sociedades cooperativas; levando em conta as relações sociais, culturais e econômicas, tanto no estudo da situação atual quanto no entendimento das influências do passado; é uma tarefa complexa. Antes de tudo, é necessário entender as discussões que perpassam os temas de raça e gênero, além de compreender a questão da representatividade desses marcadores sociais.

O Brasil foi o último país a formalizar o fim do escravismo no século XIX, contudo não buscou instituir nenhuma política de socialização dos negros escravizados na organização social a ser instaurada após a Lei Áurea. No lugar disso, buscou incentivar a abertura das fronteiras para imigrantes de determinadas partes da Europa ${ }^{7}$ na tentativa de alterar a composição racial brasileira, uma vez que o subdesenvolvimento do país era tido como uma consequência do número elevado de negros aqui existentes (SANTOS, 1997).

Atualmente, as discussões sobre o racismo e o antirracismo no Brasil têm sido intensificadas. O primeiro presidente a afirmar a existência de um problema em relação à questão racial no país, Fernando Henrique Cardoso (1995-2003), abriu caminho para que o tema não ficasse somente na discussão teórica e para que políticas públicas fossem criadas na intenção de solucionar/minimizar o problema. Entretanto a simplificação de termos que convergem na discussão colabora para o enfraquecimento de argumentos e, em certos casos, com a não compreensão da gravidade do problema.

Durante muito tempo, o significado de raça teve ligação direta com uma

\footnotetext{
${ }^{7}$ Não eram todas as pessoas do continente europeu bem-vindas segundo essas políticas. Os africanos e asiáticos também estavam proibidos de entrar no país.
} 
questão biológica. Até o século XIX era algo que determinava biologicamente quais indivíduos eram superiores e quais eram inferiores aos demais, quem tinha maior capacidade de se desenvolver intelectualmente e quais eram feitos apenas para realizar trabalhos braçais (GOMES, 2005). Como é relatado pela história, a superioridade intelectual e a física foram concedidas aos brancos e aos negros foi determinada uma condição de subalternidade, fazendo com que estes fossem coisificados e escravizados durante anos. Entretanto, como a ciência biológica não comprova a existência de uma diferenciação genética dos seres humanos, a relação da raça com a biologia humana foi rompida (SANTOS, 2004).

O conceito de raça, agora, tem uma perspectiva social e cultural, estando ligado à construção da identidade do indivíduo e da formação de sua consciência política. Isso significa que raça é uma construção social e se transforma de acordo as mudanças sociais e pelos contextos vividos. Um dos principais termos ligados a raça é o racismo. No Brasil, sempre que pronunciado, esse termo remete à escravidão e aos preconceitos raciais sofridos pelas pessoas negras. De acordo com Sales Augusto de Santos (2004, p. 4):

racismo é a doutrina ou o ideário que atribui inferioridade ou superioridade biológica e cultural a determinados grupos sociais, especialmente em função do fenótipo e/ou cor/raça destes grupos, proporcionando assim o surgimento de crenças, atitudes e práticas que têm como resultado discriminação e desigualdades raciais.

Corroborando com o autor, o racismo sempre possui dois lados, por isso não é possível afirmar que este afeta somente os negros. Apesar disso deve-se reconhecer que são os negros os mais atingidos, evidenciado pelo racismo de resultados existente no Brasil. Este termo significa que, na sociedade brasileira, não é vista a prática do preconceito racial, mas este é evidenciado nas estatísticas, que mostram 
que os pretos e pardos apresentam "condições de vida semelhantes e igualmente inferiores quando comparadas ao grupo branco" (CARNEIRO, 2011 p. 67).

Quando o preconceito racial é o fator que impede as pessoas de acessarem seus direitos sociais, está ocorrendo uma discriminação racial. A melhor forma de diferenciar esses dois conceitos, de acordo com Santos (2004), é perceber que o primeiro nem sempre será externalizado, enquanto o segundo pode ser tido como uma consequência do preconceito racial.

A discriminação e exclusão que atingem os negros são acentuadas quando combinadas com o fator de gênero. Isto é, as mulheres negras são ainda mais estigmatizadas mediante a sociedade, sendo que as mesmas "compõem, em grande parte, o contingente de trabalhadores em postos de trabalho considerados pelos especialistas os mais vulneráveis do mercado" (CARNEIRO, 2011, p. 129).

As discussões sobre gênero também necessitam ter alguns pontos mais especificados para que não haja má interpretação do problema de desigualdade existente entre homens e mulheres. A influência de perspectivas essencialistas e patriarcais, que estabelecem o papel da mulher como ser inferior e pautado pela vontade dos pais ou maridos, é nítida na formação de inúmeras culturas, inclusive a brasileira. Essas ideologias contribuíram para o fortalecimento do histórico de subordinação, dominação e exclusão das mulheres de espaços públicos e privados, além da subtração de direitos dos quais deveriam gozar (BRUMER; DOS ANJOS, 2012).

Os significados construídos social e culturalmente para as ações de homens e mulheres foram baseados em diferenças biológicas e sexuais contribuindo para a inferiorização das últimas e dando margem para as desigualdades políticas, econômicas e sociais entre os mesmos. Entretanto gênero não pode ser entendido como sinônimo de diferenças biológicas, apesar do conceito ter seu fundamento nestas questões (PEREIRA, 2004 apud OLIVEIRA - CRUZ, 2018). De acordo com Scott 
(1990) apud Pedro (2005, p. 86), o gênero é um elemento constitutivo de relações sociais baseado nas diferenças percebidas entre sexos, e o gênero é uma forma primeira de significar as relações de poder".

Os jogos de poder existentes nas relações de gênero e raça não podem ser entendidos apenas por superioridade, dominação e coerção, quando na verdade estes são elementos constitutivos em termos culturais e simbólicos que estabelecem a estruturação social como vemos hoje (HALL, 1997). Por isso, esclarecer a questão do poder dentro das relações raciais e de gênero representa um avanço essencial para a inclusão das mulheres e dos negros em uma esfera política, na qual seriam discutidos assuntos que dizem respeito a estes e às suas dificuldades diárias na sociedade.

Na realização da análise de gênero, ainda é preciso entender que ele é uma construção cultural que sofre influência do meio onde ocorre, das relações sociais que o permeiam e das diferenças entre os espaços e tempos históricos. Segundo Dias e Valle (2011), a categoria gênero é constituída por quatro elementos fundamentais: os símbolos culturais impostos na vida social que influenciam diversas representações; os conceitos normativos que revelam as interpretações dos símbolos através das instituições; as organizações e intuições sociais onde ocorrem as interações sociais e a chamada identidade subjetiva. É por meio da análise dos quatro elementos listados pelos autores, que são percebidas a exclusão e a vulnerabilização de certos grupos sociais, dentre eles as mulheres pobres e negras.

A exclusão que atinge as mulheres dá-se, muitas vezes, simultaneamente, por meio do trabalho, da classe social, da cultura, da etnia, da idade, da raça, o que torna difícil atribuir a tal fenômeno um aspecto específico, na medida que combina vários elementos da exclusão social (DIAS; VALLE, 2011 p.93). 
Nesse contexto, é perceptível a necessidade de tornar evidente a relação existente entre raça, gênero e outros marcadores sociais. Um exemplo nítido são os movimentos sociais rurais, nos quais verifica-se a carência de uma sistematização voltada para suas especificidades quando se trata da luta de classes e da igualdade racial e de gênero. Ao estudar as representações femininas na mídia, deve-se atentar para as particularidades apresentadas em cada grupo social.

\subsection{Comunicação, diversidade e representação}

Aos negros foram interditados o direito à imagem "sempre minoritária ou inexistente na publicidade nacional. Impera aí um imaginário social em que a loirização se tornou o ideal de ego da sociedade em detrimento de sua realidade racial" (CARNEIRO, 2011, p.164). No tocante às mulheres, essas geralmente são incorporadas na publicidade como "emotivas, passivas, dóceis ou sensuais e homens como sujeitos racionais, viris e provedores do lar" (OLIVEIRA-CRUZ, 2018, p.93).

Diante do cenário exposto pelas autoras, a palavra diversidade neste trabalho é utilizada na concepção política de reivindicação por representação e por igualdade. Distancia-se, portanto, do seu emprego como expressão de fragmentação ou do discurso empresarial de "boas práticas", que retira a sua conotação de luta. Nesses termos, corrobora Martin-Barbero (2009, p.154) ao sublinhar que é impossível falar em diversidade/alteridade sem “assumir o profundo vínculo da 'diferença' com a desigualdade social e a discriminação política, ou seja, colocando em primeiro plano a indispensável ligação entre direitos culturais e sociais" (grifo nosso).

A desigualdade pautada por Martín-Barbero (2009) no Brasil é visível nos indicadores sociais. No que tange aos negros, são os que estão na pior condição socioeconômica. Os dados sobre rendimento apontam que as famílias negras possuem renda per capita média que representa a metade do ganho de uma família branca. Além da renda, esse grupo racial está mais sujeito à violência e ao desemprego (IPEA, 2011, 2017). 
Essas assimetrias sociais e de dominação existentes na sociedade se refletem na comunicação. Da mesma forma, ela revalida desigualdade ao conformar o imaginário social com representações simplificadas.

O conceito de representação adotado neste trabalho é o de Stuart Hall (2016, p.34), entendida não como mero reflexo da realidade. Representação "é a conexão entre conceitos e linguagem que permite nos referirmos ao mundo 'real' dos objetos, sujeitos ou acontecimentos, ou ao mundo imaginário de objetos, sujeitos e acontecimentos fictícios". Indivíduos que compartilham a mesma cultura, lembra Hall, possuem mapa mental semelhante. Isso significa que interpretam os signos de forma parecida. Tal pensamento serve para ilustrar que o signo "homem ou mulher negra" dificilmente estaria conectado, ao menos para a maioria das pessoas, ao conceito de sucesso na sociedade brasileira, onde esse grupo racial costuma estar associado a imagens pejorativas.

Na concepção construtivista de representação ${ }^{8}$ adotada por Hall $(2016$, p.48), as coisas não significam por si mesmas. "Nós construímos sentido, usando sistemas representacionais - conceitos e signos. [...] Não devemos confundir o mundo material, onde as coisas e pessoas existem, com as práticas e processos simbólicos pelos quais representação, sentido e linguagem operam".

No sistema de representação, a estereotipagem é uma das formas de dar sentido à linguagem. "[...] Os estereótipos referem-se tanto ao que é imaginado, fantasiado, quanto ao que é percebido como 'real' [...]" (HALL, 2016, p. 200). Esse processo envolve representação, diferença e poder. Afinal quem pode classificar e marcar determinados grupos? Na representação, negras e negros, geralmente, são reduzidos a algumas profissões (empregados domésticos e/ou ao talento para o esporte) ou têm o perfil associado à criminalidade. As mulheres são ainda colocadas

\footnotetext{
${ }^{8}$ Hall (2016, p.47-48) menciona também a abordagem reflexiva de representação na qual a linguagem funciona como espelho que reflete o sentido como verdadeiro do mundo. Já na representação intencional de representação é o autor que impõe "seu único sentido no mundo, pela linguagem".
} 
como corpos sexualizados ou como cuidadoras da família.

Em suma, os textos e imagens empregados pela comunicação não são utilizados aleatoriamente ou são entretenimento inocente. Eles regulam e ordenam a sociedade ao mostrar modelos de beleza, padrões de feminilidade e masculinidade assim como paradigmas do que é ser bem-sucedido ou fracassado (KELLNER, 2001). Nessa perspectiva, as narrativas midiáticas são centrais para entender a exteriorização do racismo e do sexismo. Conforme enfatiza Borges (2012, p.186), “as questões raciais visadas nos meios de comunicação podem nos conduzir a entender as múltiplas formas de retroalimentação do racismo".

Diante das críticas ao padrão eurocêntrico da comunicação, como alcançar ou incorporar a diversidade? De acordo com a Unesco (2002), a diversidade se manifesta na originalidade e na pluralidade de identidades que caracterizam os grupos e as sociedades que compõem a humanidade. Sueli Carneiro (2011, p.71) corrobora com a discussão ao afirmar que não basta inserir um negro entre os brancos para ter pluralidade, tampouco a representação de negros como um grupo homogêneo. "A branquitude é, portanto, diversa e policromática. A negritude, no entanto, padece de toda sorte de indagações". Trazendo a indagação de Carneiro para o campo da comunicação, pode-se inferir que a busca pela diversidade negra na comunicação precisa contemplar a variedade policromática a negritude, faixa etárias, orientação sexual e classe social.

Nas peças publicitárias, é possível perceber que as representações que contemplam a diversidade existente no Brasil ainda são permeadas por estigmas e desinformação sobre os grupos que representam (MORARES et al., 2016). A implicação da reprodução destes estereótipos alimenta uma falsa ideia de diversidade, uma vez que há minimamente representação de todos os grupos sociais. Tais ações podem ainda contribuir para a manutenção da hegemonia existente. Como afirma Hall (1997), o aumento de representações de negros não necessariamente 
pode ser tido como algo positivo, uma vez que estes podem aparecer com um perfil negativo e rejeitado pela sociedade, o que só iria reforçar os preconceitos já existentes.

No Brasil, é possível perceber, por parte das empresas, uma tentativa de representar todos os grupos sociais, mas sem deixar de atender às demandas de uma sociedade conservadora, conforme afirma Oliveira (2016 p. 6) ao analisar a reação dos consumidores à campanha "Casais" ${ }^{\prime 9}$ da rede de cosméticos e perfume brasileira O Boticário.

Por se tratar da primeira campanha publicitária voltada ao público LGBTTI em horário nobre e com abrangência nacional, não poderia ser outra a estratégia da marca, [...]. A cautela é sempre ligada ao temor da rejeição de consumidores, neste caso, dos setores mais conservadores.

Outro ponto a ser destacado é a tentativa, por parte de muitas organizações, de promover ações e representações acerca da diversidade social para adquirirem uma competência distintiva e não serem criticadas por promoverem apenas um determinado grupo social (BITTELBRUN, 2016). Atitudes como essa não contribuem para a democratização do processo de comunicação. A exclusão e/ou caracterização de negros, mulheres, obesos e demais grupos sociais minoritariamente representados (já que não é possível afirmar que alguns desses são minoria na população brasileira) faz com que a comunicação não seja um instrumento de propagação da igualdade social (MIRANDA, 2016).

\footnotetext{
${ }^{9}$ Campanha para o dia dos namorados 2015 da linha do perfume Egeo. Exibida em 24/05/2015 no intervalo do Fantástico na Rede Globo. No vídeo, homens e mulheres vão comprar presentes e se preparam para um encontro romântico. São quatro casais de meia idade. A surpresa ocorre durante o abrir da porta: dos quatro casais, um é gay e o outro é lésbico. Há um tom bastante intimista ao som da canção "Toda forma de forma de amor", de Lulu Santos, numa intencionalidade pretensamente natural, disposto a realçar a diversidade de relacionamentos de forma não apelativa. Os casais se abraçam, não há diálogos, trocam os perfumes, mas não se beijam (OLIVEIRA. 2016 p. 4).
} 


\section{PROCEDIMENTO METODOLÓGICO}

Para a realização desta pesquisa foi realizado um levantamento bibliográfico que, de acordo com Cervo e Bervian (1983), consiste na tentativa de explicar um problema por meio de referências teóricas que já foram publicadas, principalmente em livros e artigos científicos. Buscamos por publicações sobre comunicação e diversidade no portal periódicos Coordenação de Aperfeicoamento de Pessoal de Nível Superior (Capes) e no site do portal brasileiro de publicações cientificas em acesso aberto (Oásisbr), a pesquisa teve como recorte temporal cinco anos (entre janeiro de 2012 e agosto de 2017). Nesse período, foram encontradas apenas 13 publicações, sendo que destas apenas uma é uma tese e duas são dissertações, e os demais trabalhos são artigos científicos.

A seleção do material para pesquisa empírica se deu com os vídeos publicados pelas cooperativas Sicoob e Cresol em seus canais no YouTube, de abril a outubro de 2017. Foram encontrados 26 vídeos no perfil Sicoob Oficial e 54 no TV Cresol. Os audiovisuais foram categorizados em: institucionais; mercadológicos; formação e informação; educação cooperativista. Dentro de cada categoria, foram selecionados para análise os dois vídeos que receberam o maior número de visualizações.

A sistematização dos dados e a conclusão do diagnóstico proposto deu-se pelo método de análise de conteúdo. Segundo Bardin (2011), esse método consiste em um conjunto de técnicas de análise de comunicações, que faz uso de procedimentos metódicos e objetivos de descrição do conteúdo das mensagens, indicadores (quantitativos ou não) que possibilitem a inferência de conhecimentos relativos às condições de produção/recepção das mensagens.

Com a intenção de entender as ideais por trás das representações midiáticas estudadas, analisar as variáveis e as circunstâncias históricas, mediante as quais este estudo se dá, adotou-se uma pesquisa qualitativa, que possibilita estabelecer uma 
relação dos papéis que os agentes sociais desempenhavam e desempenham atualmente, e assim apontar suas transformações. Conforme confirmam Lakatos e Marconi (2007) "[...] as instituições alcançaram na sua forma atual através de alterações de suas partes componentes, ao longo do tempo, influenciadas pelo contexto cultural particular de cada época." Dessa forma é possível identificar quais questões do cotidiano e da sociedade estão ligadas direta e indiretamente as representações dos negros e das mulheres nas cooperativas analisadas.

\subsection{Cooperativismo de crédito e comunicação}

O Sistema de Cooperativas de Crédito do Brasil (Sicoob) é composto por 466 cooperativas singulares, 16 centrais e a Confederação Nacional de Cooperativas de Crédito do Sicoob (Sicoob Confederação). Atualmente, o Sicoob possui cerca de 4,01 milhões de associados, mais de 2,6 mil pontos de atendimentos espalhados por todo o território nacional e 466 cooperativas singulares, sendo caracterizado como a maior instituição dentro do sistema de cooperativismo de crédito do país (MEINEN; PORT, 2014). A organização criou um canal no YouTube em maio de 2011 , denominado Sicoob Oficial, com a intenção de divulgar vídeos comerciais e institucionais que abrangessem assuntos como poupança e educação cooperativista. O canal, até agosto de 2018, havia publicado 123 vídeos, contava com cerca de 8 mil perfis inscritos e 6,2 milhões de visualizações.

Constituída em 1995 no Paraná com a intenção de promover a inclusão financeira e o desenvolvimento social da região, o Sistema de Cooperativas de Crédito Rural Solidário do Brasil (Cresol) atualmente possui cerca de 105 pontos de atendimentos espalhados por nove estados brasileiros, 32 cooperativas singulares filiadas e cinco bases regionais de serviços. Grande parte da estrutura encontra-se no Sul do Brasil, segundo dados divulgado no portal digital da entidade. O sistema Cresol tem se destacado pelos serviços e transformações proporcionados aos seus associados e, por isso, é considerado o maior sistema de crédito solidário do Brasil 
(MEINEN; PORT, 2014). Em 2010, foi criado o canal TV Cresol na rede social YouTube, responsável por fornecer informações de forma ilustrada e conhecimento sobre o movimento cooperativista, em especial sobre o ramo de crédito solidário. O canal possuía 234 vídeos publicados e cerca de 86,5 mil visualizações até agosto de 2018 . 0 número de inscritos não estava disponível.

Baseado no levantamento realizado nos canais de ambas as centrais no YouTube, os materiais publicados foram separados em categorias. A organização e o propósito de cada uma foram desenvolvidos a partir do objetivo desta pesquisa. Ao todo, são quatro classificações assim divididas:

- Institucional - aqui estão os vídeos que visam a promoção da imagem da organização evidenciando sua visão, missão e valores bem como tornam suas ações públicas;

- Mercadológico - neste grupo, estão reunidas as mídias que procuram persuadir os cooperados/clientes a utilizarem seus produtos e serviços;

- Educação cooperativista - nesta categoria, são agrupados os vídeos que levavam os princípios e visões do cooperativismo de crédito ao público de interesse;

- Formação e informação - estão agrupados aqui os conteúdos que levam informações relevantes para o público, nem sempre sendo voltadas para o cooperativismo.

Durante os seis meses analisados, a Cresol disponibilizou 54 vídeos no seu canal no YouTube, enquanto o Sicoob, no mesmo período, publicou 26. Deste último vale ressaltar que existem cinco vídeos produzidos pelo Banco Central do Brasil (Bacen) e que foram divulgados devido a recomendação da autarquia. Ainda tratando das mídias disponibilizadas no canal Sicoob Oficial, cabe destacar que não foi colocado qualquer vídeo institucional no período. O último conteúdo desta categoria datava, até a finalização desta pesquisa, de 25 de outubro de 2016. 
A quantidade que cada instituição disponibilizou em cada classe pode ser observada no quadro 1:

\section{Quadro 1: Postagens Cresol e Sicoob por categoria}

\section{Institucional Mercadológico Educação Formação e \\ Cooperativista Informação}

\begin{tabular}{|l|c|c|c|c|}
\hline Cresol & 5 & 29 & 2 & 18 \\
\hline Sicoob & 0 & 18 & 2 & 6 \\
\hline
\end{tabular}

Fonte: elaborado com dados da pesquisa.

Por meio do quadro 1 acima, é possível perceber que a comunicação organizacional dessas cooperativas tem seu foco no âmbito mercadológico. O Sicoob Oficial é o canal que mais publica mídias que tratam de seus produtos e serviços (quase $70 \%$ de suas ações no YouTube). Já a Cresol pode ser caracterizada como a instituição que demonstra uma maior dedicação em realizar ações de comunicação mais diversas com seu público de interesse, apesar de quase $54 \%$ de suas publicações se enquadrarem como mercadológicas. As demais categorias possuem mais conteúdos se comparadas às do canal pertencente ao Sicoob.

A regularidade das postagens dos vídeos no canal TV Cresol é de pelo menos duas publicações por semana, sendo que o quadro Expedição $\mathrm{Cresol}^{10}$ (que abrange quase todos os conteúdos da categoria produtos e serviços - comunicação mercadológica) é o que mais se destaca. Já o Sicoob não possui uma periodicidade, quando lançam uma campanha publicam todos os vídeos em um só dia. As publicações com conteúdo único, em sua maioria, são postadas semanalmente. Entretanto, durante o período analisado, existiam postagens com um mês de espaçamento entre si.

\footnotetext{
${ }^{10}$ Programa semanal do canal TV Cresol no YouTube, no qual são realizadas visitas aos cooperados para que eles relatem suas histórias e experiências com o trabalho prestado pela cooperativa.
} 
Apesar de ser a instituição que mais realizou ações de comunicação pelo YouTube, a Cresol não possui um número de visualizações tão significativo quanto o do Sicoob. A quantidade de views de cada canal pode refletir sua abrangência territorial em termos de agências para prestação de serviços. O vídeo mais visualizado do Sicoob, durante o período estudado, possui uma escala na classe dos milhares - 140.462 -enquanto o da Cresol, apenas 624 views.

\subsection{Diversidade na comunicação do cooperativismo de crédito}

Apesar dos princípios do movimento cooperativista indicarem preocupação com a formação, a educação e com o desenvolvimento social, a pesquisa revela que a representatividade racial na comunicação, em ambas as cooperativas de crédito, é praticamente inexistente. $\mathrm{O}$ protagonismo de pessoas negras pode ser tido como nulo, na maioria das vezes em que aparecem, não possuem falas. Dentre o material analisado, a presença de não brancos acontece, mesmo que de forma superficial, mais frequentemente nos produtos pertencentes à Cresol. O Sicoob; que por estar presente em todo território nacional deveria, em tese, estar mais empenhado em representar toda a diversidade existente no Brasil; não promoveu a fala de um preto ou pardo em nenhum audiovisual.

O único vídeo ${ }^{11}$ no qual uma pessoa negra tem poder fala enquadra-se na categoria institucional do canal TV Cresol. O mesmo tem duração de 16 minutos e 40 segundos, entretanto a fala da cooperada, que é negra, é dividida em duas partes e totaliza apenas um minuto e três segundos. Neste mesmo audiovisual, 17 homens brancos têm falas, em contrapartida apenas duas mulheres são ouvidas (uma branca e outra negra), sendo que a cooperada de pele branca estava ao lado de seu companheiro e sua fala somente ocorre após a do homem.

\footnotetext{
${ }^{11}$ Vídeo: "10 anos Cresol Fervedouro", disponibilizado no dia 17 de abril de 2017 no canal da Cresol na rede social YouTube.
} 
No canal Sicoob Oficial, a mídia ${ }^{12}$ protagonizada por um negro é caracterizada como mercadológica e os personagens são animações, como pode ser visualizado na imagem:

Imagem 1: Representação do negro no audiovisual do Sicoob

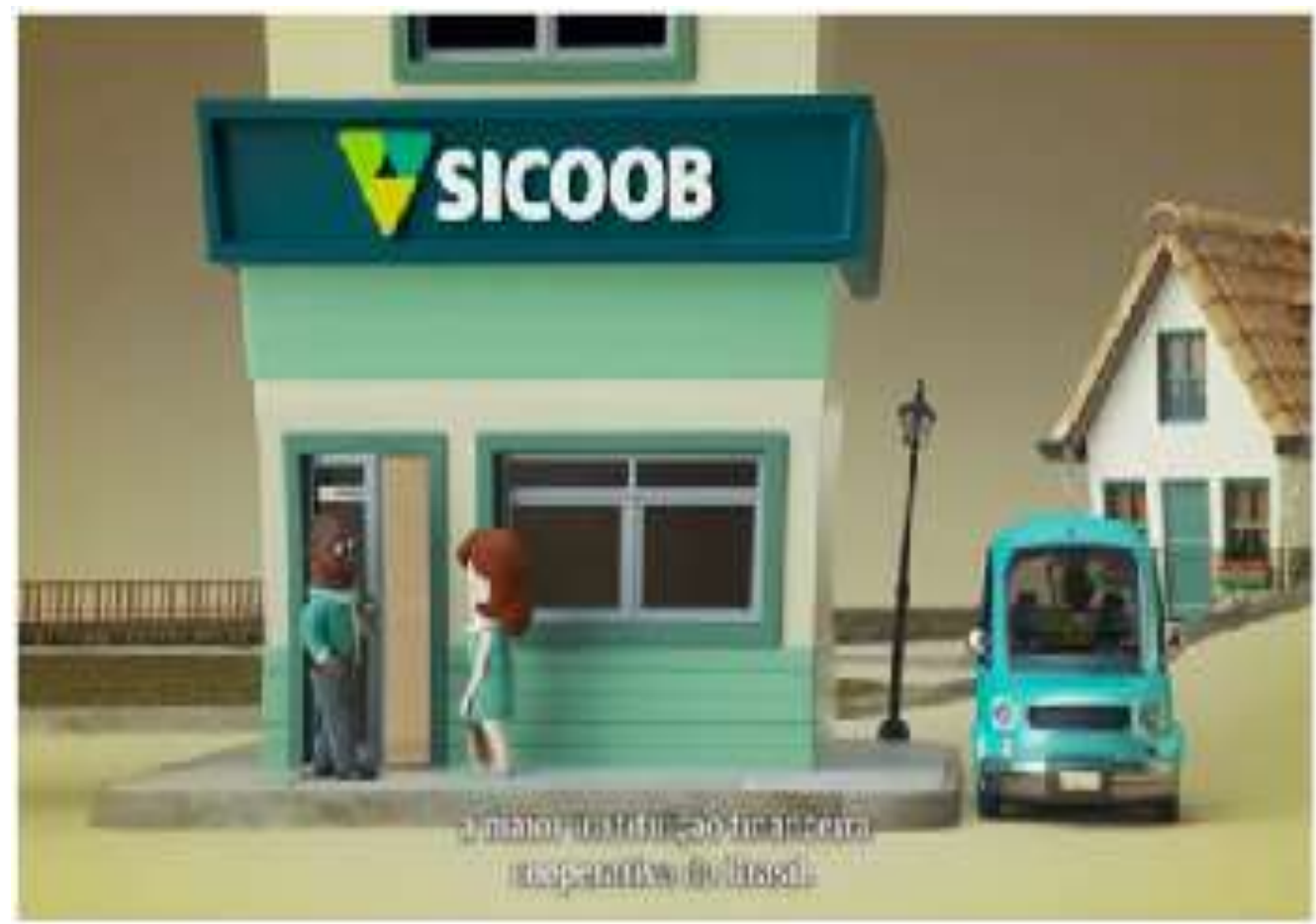

\section{Slanob consóticios}

Fonte: Imagem retirada do vídeo "Sicoob Consórcios" do canal do YouTube "Sicoob Oficial”"13.

O vídeo é narrado por uma voz masculina e os personagens não falam. Eles buscam contratar um consórcio na cooperativa para realizar o sonho de comprar um carro. Com os serviços oferecidos pela cooperativa, isso torna-se possível. O homem preto aparece dirigindo um veículo popular com sua companheira no banco do carona. Diante de tantos serviços oferecidos na cooperativa, como cartão de crédito, financiamentos, investimentos e cheques, o negro (animação) aparece apenas no anúncio de um dos produtos mais populares. O que se questiona é: as pessoas pretas

\footnotetext{
${ }^{12}$ Vídeo: "Sicoob consócios", disponibilizado no dia 30 de junho de 2017 pela cooperativa Sicoob em seu perfil no YouTube.

${ }^{13}$ Disponível em: https://www.youtube.com/watch?v=aYdw683qJ5c. Acesso em: 10 de ago. 2018.
} 
e pardas utilizam apenas os empréstimos e consórcios em uma cooperativa? Ao representar somente uma vez um negro e sob estas circunstâncias, a cooperativa contribui para a formação de uma "imagem do outro" que padroniza pessoas de um mesmo grupo racial.

Dentre as principais dificuldades enfrentadas na busca para a realização de uma representação mais diversa e menos estigmatizada, encontra-se o fato de muitas organizações não compreenderem (ou não buscarem compreender) como isso pode ser realizado, conforme afirma Sueli Carneiro (2011, p. 70-71):

Uma das características do racismo é a maneira pela qual ele aprisiona o outro em imagens fixas e estereotipadas, enquanto reserva para os racialmente hegemônicos o privilégio de ser representados em sua diversidade. Assim, para os publicitários, por exemplo, basta enfiar um negro no meio de uma multidão de brancos em um comercial para assegurar suposto respeito à diversidade étnica e racial e livrar-se de possíveis acusações de exclusão social das minorias. Um negro ou japonês solitários em uma propaganda povoada de brancos representa o conjunto de suas coletividades. Afinal, negro e japonês são todos iguais, não é mesmo?

A presença de um ou dois negros em meio a várias pessoas brancas, não pode ser entendida como uma ação que valoriza a diversidade racial. Em vez disso, essa ação pode contribuir para a criação e a reafirmação de estereótipos sobre os mesmos. A Convenção sobre a Proteção e a Promoção da Diversidade das Expressões Culturais da Unesco em 2005 procurou discutir quais medidas deveriam ser tomadas para que a representatividade de todos os grupos sociais ocorresse. O primeiro passo para que isso aconteça no Brasil é a compreensão de que grande parte da população que irá receber os conteúdos não está sendo representada em sua pluralidade. 
Quando analisados na perspectiva de gênero, os produtos disponibilizados pelas cooperativas também reproduzem padrões machistas e paternalistas. A Cresol, cooperativa voltada principalmente para a população rural, é a que mais retrata situações com padrões de gênero e de submissão das mulheres. Em diversos vídeos da cooperativa, as mulheres aparecem ao lado de seus companheiros apenas como composição figurativa, não são nomeadas/apresentadas e, por diversas vezes, não chegam a olhar diretamente para a câmera, como vemos na imagem a seguir:

Imagem 2: A posição das mulheres nos vídeos publicados pela Cresol

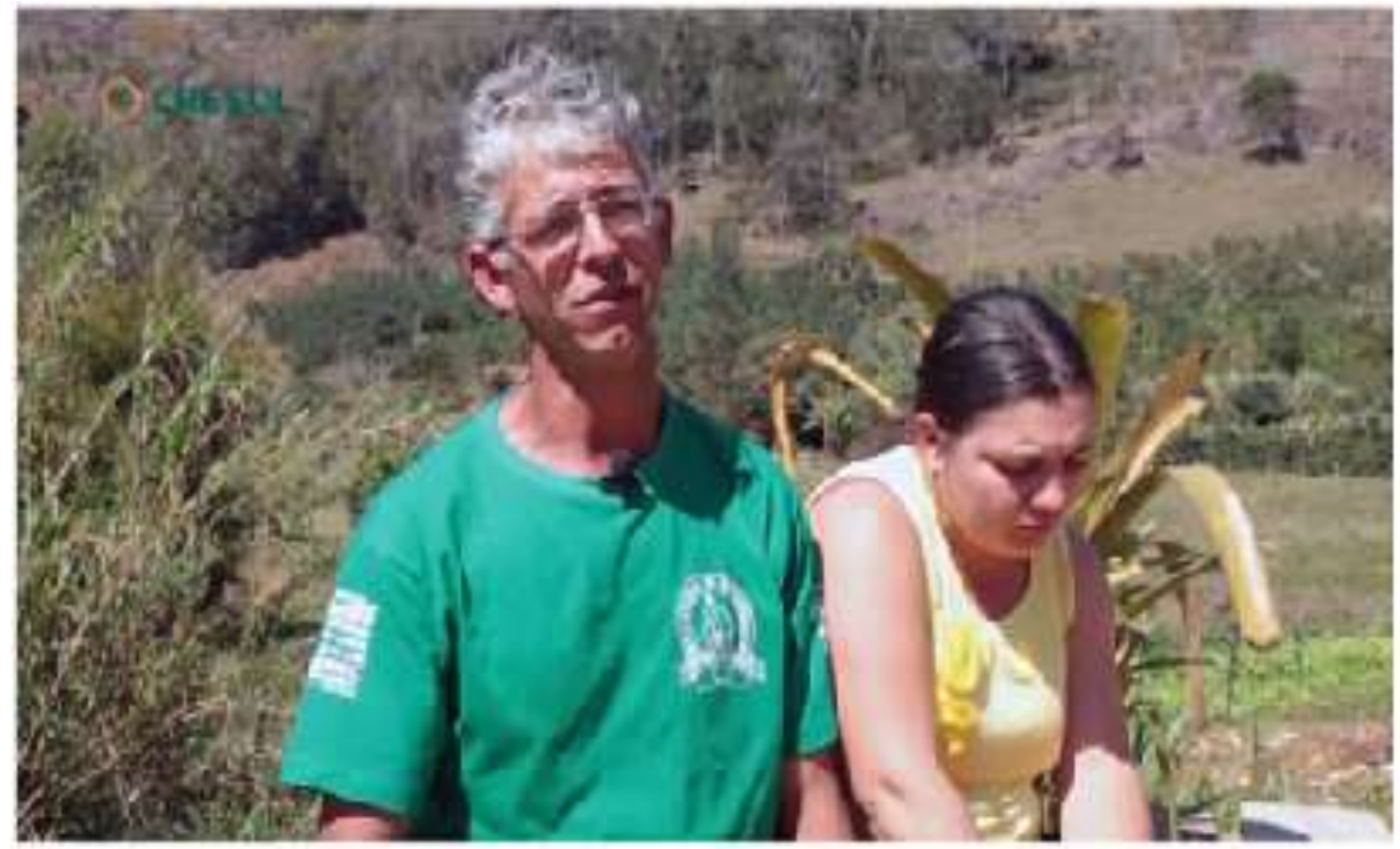

\section{C anos Sreacl Fervedouro'MG}

Fonte: Imagem retirada do vídeo "10 anos Cresol Fervedouro/MG" do canal do YouTube "TV Cresol". ${ }^{14}$

Quando as cooperadas realizam falas, na maioria das vezes, restringem-se a descrever os benéficos pessoais que alcançaram por meio da atuação da cooperativa, como na fala de Delenice de Feitas no vídeo institucional "10 anos de Cresol Fervedouro/MG":

\footnotetext{
${ }^{14}$ Disponível em: https://www.youtube.com/watch?v=LKo_TqtLacl. Acesso em: 10 de jul. 2018.
} 
Cresol, ela tem ajudado muitos produtores e aí foi por isso que a gente começou já. Primeiro, desde começar a fazer a casa, porque a gente morava na casa da mãe dele, e depois que nós fizemos aqui que nós passamos a falar assim: hoje nós temos uma casa. E graças à Cresol (FREITAS, 2017) $)^{15}$

O papel de apresentar o trabalho realizado na propriedade rural é concedido apenas ao homem. O trabalho da mulher no âmbito rural sempre foi significativo, entretanto, na maioria das vezes, é tido como uma ajuda ou contribuição, poucas vezes é identificado como fundamental para a realização do trabalho produtivo (BRUMER; DOS ANJOS, 2012). Além disso, a cooperativa desenvolve, em seu canal, dois quadros que possuem uma postagem regular: o Momento Cresol $^{16}$ e o Expedição Cresol. O primeiro é apresentado por um homem branco e o segundo, por duas mulheres brancas, loiras e magras.

Apesar de não reproduzirem cenas tão patriarcais como as da Cresol, as mídias publicadas no canal Sicoob Oficial contêm padrões de gênero e expõem visões sexistas. Em uma produção ${ }^{17}$ que visava explicar determinados conceitos do movimento cooperativista, uma menina aparece brincando de cozinhar para realizar determinada ação. Uma outra campanha ${ }^{18}$, relaciona diretamente a mulher com o consumismo e traz para ilustrar uma jovem branca, magra e de cabelos longos como modelo a ser seguido/alcançado. A seguir estão as imagens 3 e 4 retiradas das respectivas mídias:

\footnotetext{
${ }^{15}$ Disponível em: https://www.youtube.com/watch?v=LKo_TqtLacl\&t=699s. Acesso em: 10 de jul. 2018.

${ }^{16}$ Quadro apresentado semanalmente no canal TV Cresol, sendo utilizado para que a cooperativa apresente seus projetos e realizações, bem como oferece espaços para que os cooperados tirem suas dúvidas sobre os serviços prestados pela mesma.

${ }^{17}$ Vídeo: "Sofia/O que é economia compartilhada", mídia disponibilizada no canal Sicoob Oficial no YouTube no dia 27 de setembro de 2017.

${ }^{18}$ Vídeo: “Duas vezes Judite?", produção do Bacen e reproduzida no canal do Sicoob em 8 de maio de 2017, devido recomendação da autarquia.
} 
Imagem 3: Reprodução de padrão de gênero

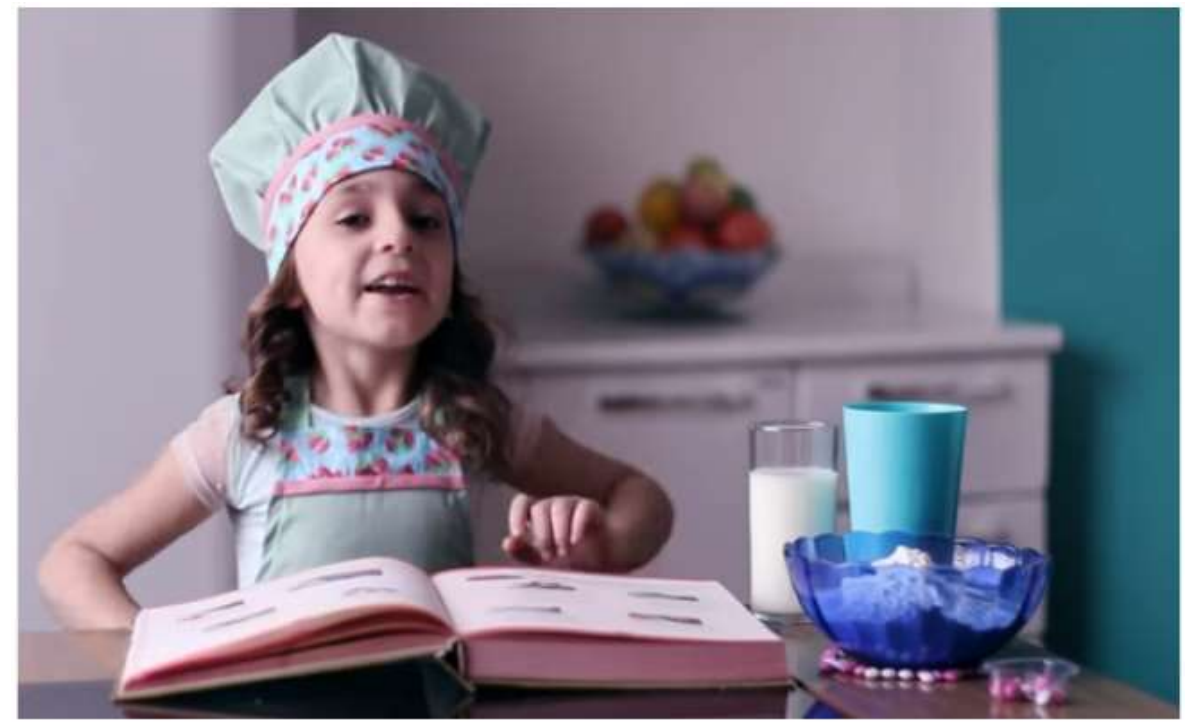

\#façaparte

Sofia I 0 que é Economia Compartilhada

Fonte: Imagem retirada do vídeo "O que é Economia Compartilhada" do canal "Sicoob Ofical" no YouTube. ${ }^{19}$

Imagem 4: Beleza e consumo

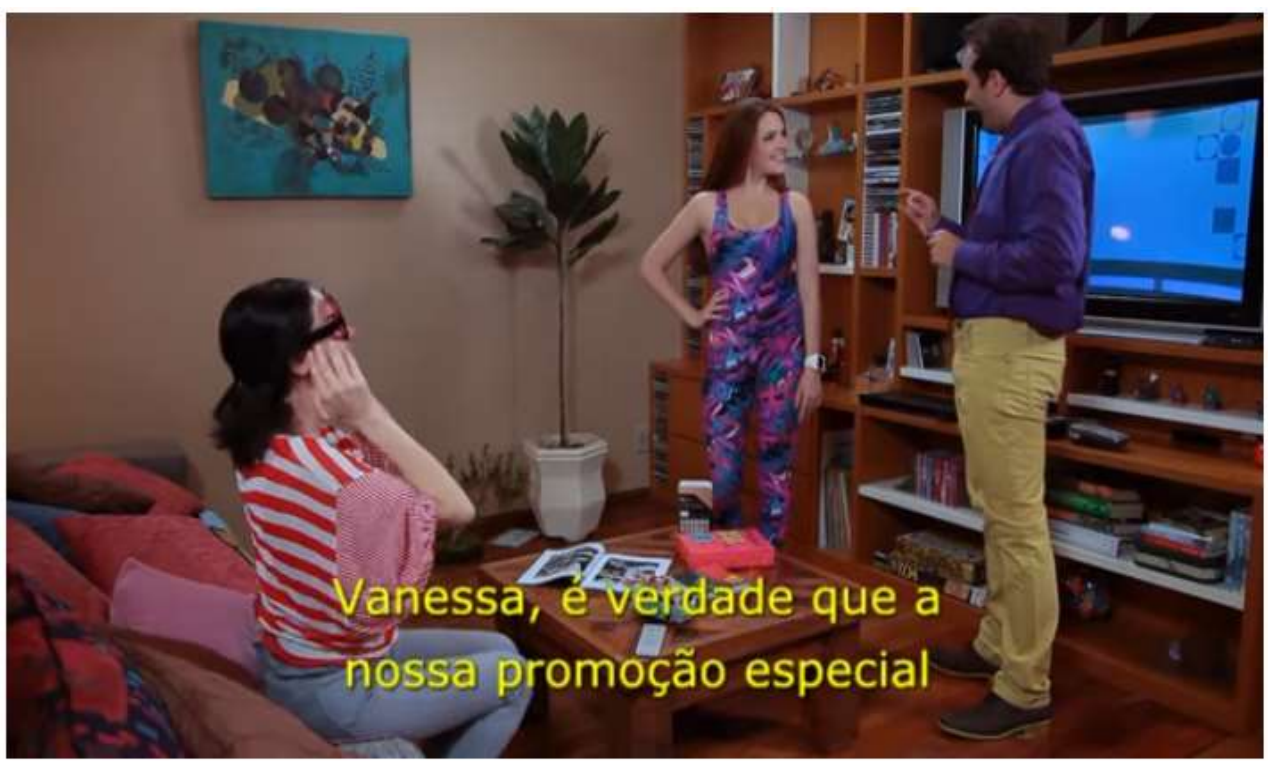

Duas vezes Judite

Fonte: Imagem retirada do vídeo "Duas vezes Judite" do canal "Sicoob Ofical" no YouTube. ${ }^{20}$

\footnotetext{
${ }^{19}$ Disponível em: https://www.youtube.com/watch?v=Fp8aGP6vPoo. Acesso em: 10 de jul. 2018.
} 
No audiovisual do qual foi retirada a imagem 3, a menina irá explicar o que é economia compartilhada por meio de uma receita de bolo, reforçando a ideia de que os afazeres domésticos são de responsabilidade feminina e de que é preciso ensinálos desde criança. A associação das mulheres com as tarefas que envolvem o cuidado é caracterizada como padrão de gênero, uma vez que, exceto ações limitadas biologicamente como gravidez e aleitamento materno, todas as tarefas do âmbito do cuidado podem ser realizadas por pessoas de ambos os sexos (OLIVEIRA-CRUZ, 2018).

A imagem 4 foi extraída de um vídeo educacional idealizado pelo Bacen e reproduzido no canal do Sicoob. O audiovisual tem cunho educacional do ponto de vista financeiro, entretanto, quanto ao seu conteúdo, há a valorização do corpo feminino magro e jovem, revalidando a concepção de que a mulher deve torna-se "escrava da beleza", uma vez que estar dentro dos padrões hegemônicos passou a ser sua obrigação. Essa padronização de referências faz como que os públicos se tornem indiferenciáveis e as ações midiáticas passem a representar apenas um tipo específico (ibidem).

De forma geral, as duas cooperativas apresentam um padrão de representação a respeito das mulheres e, como foi possível perceber, esse padrão não contempla a diversidade existente no país, muito menos acompanha os avanços das lutas feministas e negras. Ao contrário disso, o que vemos é uma propensão para um determinado grupo de mulheres padronizadas (brancas, magras, jovens) em função de diversos preconceitos existentes e em favorecimento do consumo.

Dentre todos os audiovisuais analisados, que se percebe é a reprodução de padrões conservadores. O estudo e o questionamento desses pontos são consequências de uma sociedade enraizada em normas machistas, racistas e paternalistas. Isso fez com que se enfraquecessem os perfis de negros e de mulheres idealizadores(as), autogestores(as) e capazes de se organizarem para a realização de

\footnotetext{
${ }^{20}$ Disponível em: https://www.youtube.com/watch?v=KOceoNCUehE\&t=138s. Acesso em: 10 de jul. 2018.
} 
atividades produtivas diversificadas. O movimento cooperativista não se limita unicamente a estabelecer processos de integração social e regional, mas deve também contribuir para o avanço das questões referentes às relações de raça e gênero.

\section{CONSIDERAÇÕES FINAIS}

Por meio das análises dos audiovisuais disponibilizados pela Cresol e pelo Sicoob, é possível inferir que a comunicação dessas organizações é permeada por estigmas e contribui para a validação de padrões conservadores. Pode-se afirmar que nenhuma das cooperativas em questão promove a representatividade racial. A ínfima presença de negros nos vídeos reforça a ideia de que sua intenção é apenas demonstrar uma preocupação de representar todos os grupos raciais e a diversidade, de forma a passar uma imagem de engajamento social, mas sem distanciar-se de representações mais padronizadas e das ideias hegemônicas. Reforça a "imagem do outro" quando, na única vez em que um vídeo é protagonizado por um negro, este procura vender os consórcios da cooperativa.

As representações acerca das mulheres, apesar de serem mais significativas do que as dos negros, ainda não podem ser consideradas como ferramenta de empoderamento. O que se vê é exatamente o contrário, as mulheres são esteticamente padronizadas e, muitas vezes, suas ações estão permeadas por padrões de gênero. O agravante encontra-se nas representações femininas no campo, além de não serem protagonistas nos vídeos, são colocadas em posições de submissão fazendo com que sua contribuição para a geração de renda não seja valorizada.

Em contrapartida, as organizações bancárias, tidas como mais convencionais e com uma cultura organizacional de valores tradicionais e conservadores, têm buscado realizar campanhas com maior representatividade racial e dando mais protagonismo 
às mulheres. Como exemplo temos a campanha "\#MulheresPraFrente" ${ }^{21}$ promovida pelo Bradesco, protagonizada por mãe e filhas negras, ou ainda a mídia publicitária "Vai Garota22" do banco Itaú que, além de possuir mulheres pretas e pardas, faz parte de um programa denominado "Itaú Mulher Empreendedora", que visa incentivar a ação econômica das mulheres.

Diante desta investigação realizada, cabe questionar um dos princípios do cooperativismo: interesse pela comunidade. Compreendemos que este implica não somente desenvolvimento econômico, mas também social. O que se espera é que haja uma preocupação deste setor em representar a heterogeneidade social e não estigmatizar os indivíduos. O apelo à diversidade tem sido uma pauta na sociedade contemporânea e absorvida por grandes corporações capitalistas por entenderem que ao contemplar aspectos da diversidade agregam valor às suas marcas e produtos.

\section{REFERÊNCIAS}

BARDIN, Laurence. Análise de conteúdo. São Paulo: Edições 70, 2011.

BALDISSERA, R; ARAUJO, D. C. Responsabilidade social, diversidade e marketing: o discurso Real Beleza Dove. Fronteiras-estudos midiáticos, v. 9, n. 1, p. 34-44, 2007.

BITTELBRUN, G. V. A negra que não está na capa de revista: debates sobre raça e gênero. Anuário de Literatura - UFSC. Florianópolis, v. 21, n. 1, p. 170-187, 2016.

BORGES, R. Media, racism and representation of the other: Light reflections on the image of black women. In: SILVA, Roberto Carlos; BORGES, Rosane Borges (orgs.). Mídia e Racismo. Brasília, DF : ABPN, 2012.

\footnotetext{
${ }^{21}$ Disponível em: < https://www.youtube.com/watch?v=fZxMQiYaado>. Acesso em: 20 de ago. 2018.

${ }^{22}$ Disponível em: < https://www.youtube.com/watch?v=2ziKp6EmqcA>. Acesso em: 20 de ago. 2018.
} 
BRUMER, Anita; DOS ANJOS, Gabriela. Gênero e reprodução social na agricultura familiar.

Revista Nera, n. 12, p. 6-17, 2012. Disponível em http://revista.fct.unesp.br/index.php/nera/article/view/1396/1378. Acesso em: 24 abr. 2017.

CARDOSO, O. O. Comunicação empresarial versus comunicação organizacional: novos desafios teóricos. Revista de Administração Pública (RAP). Rio de Janeiro v. 40, n.6, p.11231144, Nov. /Dez.

CARNEIRO, S. A miscigenação racial no Brasil. In: CARNEIRO, S. Racismo, sexismo e desigualdade racial no Brasil. São Paulo: Selo Negro, 2011.

CARNEIRO, S. A miscigenação racial no Brasil. In: CARNEIRO, S. Negros de pele clara. In: CARNEIRO, S. Racismo, sexismo e desigualdade racial no Brasil. São Paulo: Selo Negro, 2011.

CARNEIRO, S. A miscigenação racial no Brasil. In: CARNEIRO, S. O matriarcado da miséria. In: CARNEIRO, S. Racismo, sexismo e desigualdade racial no Brasil. São Paulo: Selo Negro, 2011.

CERVO, A. L.; BERVIAN, P. A. Metodologia científica para uso dos estudantes universitários. S510 Paulo: McGraw-Hill do Brasil, 1983.

DIAS, D. C.; VALLE, P. A. M.. A (des)igualdade de gênero em Goiás: trabalho e exclusão social. In: DIAS, L. O.; EL KADI, N. I.; NASCIMENTO, T. F. (org). Plantar, bordar e colher: mulheres cooperadas, diagnósticos e reflexões. Goiânia: Ed. Da PUC - Goiás, 2011. p. 93 - 107.

GOMES, N. L.. Alguns termos e conceitos presentes no debate sobre relações raciais no Brasil: uma breve discussão. In: BRASIL. Educação Anti-racista: caminhos abertos pela Lei federal $n^{\circ}$ 10.639/03. Brasília, MEC, Secretaria de educação continuada e alfabetização e diversidade, 2005. p. $39-62$.

HALL, S. O espetáculo do outro. In: HALL, S. Representação: Representações Culturais e Práticas Significativas. Londres: SAGE / Universidade Aberta, 1997.

HALL, S. O espetáculo do outro. In: HALL, S. Cultura e Representação. Tradução: Daniel Miranda e William Oliveira. Rio de Janeiro: Ed. PUC-Rio; Apicuri, 2016. 
IPEA. Retratos das desigualdades: gênero e raça. Brasília: IPEA, 2011.

IPEA. Estudo mostra desigualdades de gênero e raça em 20 anos. Disponível em: http://www.ipea.gov.br/portal/index.php?option=com_content\&view=article\&id=2952 6. Acesso em: 30 mar. 2018.

KELLNER, Douglas. Por um estudo cultural, multicultural e multiperspectívico. Bauru,SP: Edusc, 2001.

LEAL, S.. Diversidade cultural e reconhecimento no quadro de políticas de comunicação e cultura no Brasil: desafios e perspectivas para concretização da Convenção da Unesco de 2005. Política \& Sociedade, Florianópolis, vol. 16 - n 35 - Jan./Abr. de 2017.

MARCONI, M. A.; LAKATOS, E. M. Fundamentos de metodologia científica. 2007.

MARTIN-BARBERO, J. Desafios políticos da diversidade. Revista Observatório Itaú Cultural / OIC - n. 8 (abr./jul. 2009). - São Paulo, SP: Itaú Cultural, 2009

MEINEM, Ênio; PORT, Márcio. Cooperativismo financeiro: percurso histórico, perspectivas e desafios. Brasília: Editora Confebras, 2014.

MIRANDA, C. M. Jovens mulheres: desafios para construção da diversidade de representação nos meios de comunicação. Revista Observatório, Palmas, v. 2, Especial 2, p. 346-394. 2016.

MORAES, T. A. et al. Marketing e diversidade: prazer, eu existo. Revista Diálogo, Canoas, $\mathrm{n}^{\circ}$ 32, p. 203-224. 2016.

OLIVEIRA-CRUZ, M. F. de. Publicidade e desigualdade: leituras sobre gênero, classe e trabalho feminino. Porto Alegre: Sulina, 2018.

OLIVEIRA, J. A. Publicidade e diversidade sexual na campanha 'Casais' do perfume Egeo de 0 Boticário. Revista Tecer, Belo Horizonte, vol. 9, n 17, 2016.

SANT'ANA, J. V. B. A invisibilidade do negro nos produtos culturais e a formação de um imaginário social racista. Revista Eventos Pedagógicos, vol. 6, n², 15ª ed. 2015. p. 276-277. 
SANTOS, S. A.. A formação do mercado de trabalho livre em São Paulo: tensões raciais e marginalização social. 1997. 144 f. Dissertação - Programa de pós-graduação em Sociologia. Universidade de Brasília/UNB. Brasília - DF.

SANTOS, S. A. Educação: um pensamento negro contemporâneo. $1^{a}$ ed. Jundiaí: Paco Editorial, 2014. v. 1. 300 p.

SANTOS, S. A. "Racismo, Discriminação e Preconceitos". Salto para o Futuro, v. 1, p. 26-33, 2004. Disponível em: http://forumeja.org.br/sites/forumeja.org.br/files/texto_2__SANTOS_S._A_Racismo_discriminacao_e_preconceitos\%20b2.pdf. Acesso em: 15 de ago. 2017. SCOTT, J. Gênero: uma categoria de análise histórica (1990), apud PEDRO, J. M. Traduzindo o debate: o uso da categoria gênero na pesquisa histórica. São Paulo: Revista história, v.24, N.1, p.77-98, 2005.

TORQUATO, Gaudêncio. Cultura, poder, comunicação, crise e imagem. Fundamentos das organizações do século XXI. São Paulo: Cengage Learning, 2012.

UNESCO. Declaração Universal sobre a diversidade cultural. Disponível em: http://observatoriodadiversidade.org.br/site/declaracao-universal-sobre-a-diversidade-cultural/. Acesso em: 4 abr 2017. 
